\begin{tabular}{|c|c|c|}
\hline \multirow{3}{*}{$\begin{array}{r}\text { Case Reports in } \\
\text { Gastroenterology }\end{array}$} & \multicolumn{2}{|c|}{ Case Rep Gastroenterol 2017;11:155-161 } \\
\hline & $\begin{array}{l}\text { DOI: 10.1159/000463378 } \\
\text { Publisned onme: IVarch 21, } 2017\end{array}$ & $\begin{array}{l}\text { (C) } 2017 \text { The Author(s) } \\
\text { Published by S. Karger AG, Basel } \\
\text { www.karger.com/crg }\end{array}$ \\
\hline & $\begin{array}{l}\text { This article is licensed under th } \\
\text { International License (CC BY-NC) } \\
\text { Usage and distribution for commer }\end{array}$ & $\begin{array}{l}\text { nons Attribution-NonCommercial } 4.0 \\
\text { ger.com/Services/OpenAccessLicense). } \\
\text { uires written permission. }\end{array}$ \\
\hline
\end{tabular}

\title{
Acute Abdomen: A Rare Case of Ruptured Hepatocellular Carcinoma
}

\author{
Severin Gloor ${ }^{\mathrm{a}, \mathrm{b}} \quad$ Kai Oliver Jensen ${ }^{\mathrm{b}, \mathrm{c}}$ Stefan Breitenstein ${ }^{\mathrm{a}}$ \\ Christoph A. Binkert $^{d} \quad$ Eliane Angst ${ }^{\text {b, e }}$ Franc Heinrich Hetzer ${ }^{f}$ \\ ${ }^{a}$ Department of Visceral and Thoracic Surgery, Cantonal Hospital Winterthur, \\ Winterthur, Switzerland; ${ }^{b}$ Department of Surgery and Orthopedics, Cantonal Hospital \\ Schaffhausen, Schaffhausen, Switzerland; 'Division of Trauma Surgery, University Hospital \\ Zurich, Zurich, Switzerland; ${ }^{d}$ Institute of Radiology and Nuclear Medicine, Cantonal \\ Hospital Winterthur, Winterthur, Switzerland; ${ }^{e}$ Department of Visceral Surgery and \\ Medicine, Inselspital, University of Bern, Bern, Switzerland; ' Department of Surgery, \\ Spital Linth, Uznach, Switzerland
}

\section{Keywords}

Hepatocellular carcinoma - Spontaneous rupture $\cdot$ Transarterial embolization · Operative treatment

\begin{abstract}
Spontaneous ruptures of hepatocellular carcinoma (HCC) are rare. Nevertheless they may lead to difficult decisions in the emergency situation. The acute therapies include conservative treatment, transarterial embolization and surgery. Curative treatment of HCC can be achieved by liver resection solely. The decision-making depends on prognostic patient's factors, such as hepatic viral infection status, Child-Pugh grade, liver cirrhosis and number of tumors. In this case transarterial embolization was preferable as a bridging therapy prior to further diagnostics and therapy, to lower the perioperative morbidity and mortality. The therapy of these cases needs an interdisciplinary approach to choose the best possible procedure in each case.

(C) 2017 The Author(s) Published by S. Karger AG, Basel
\end{abstract}




\section{Case Reports in Gastroenterology}

Case Rep Gastroenterol 2017;11:155-161 DOI: $10.1159 / 000463378$

(c) 2017 The Author(s). Published by S. Karger AG, Basel www.karger.com/crg

Gloor et al.: Acute Abdomen: A Rare Case of Ruptured Hepatocellular Carcinoma

\section{Introduction}

Hepatocellular carcinoma (HCC) has worldwide an incidence of approximately 15 per 100,000 . Especially in developing regions, HCC is a major problem. Subsequently it has an incidence of up to 32 per 100,000 in eastern Asia, whereas it reaches an incidence of 5 per 100,000 in northern Europe. Women are less often affected than men [1]. Patients with liver cirrhosis due to any etiology and patients with non-cirrhotic liver, but with chronic hepatitis or non-alcoholic steatohepatitis are at risk for cancer development as well [2]. The incidence of HCC will increase in the next few years due to the increased incidence of liver cirrhosis in chronic hepatitis $\mathrm{B}$ and $\mathrm{C}$ and alcoholic and non-alcoholic liver disease [3]. The staging of the tumor follows the international guidelines of the WHO and the TNM classification [4].

Rupture of the tumor with subsequent intraperitoneal hemorrhage is a life-threatening condition. In patients diagnosed with HCC, rupture occurs in 3-15\%, with a high in-hospital mortality rate of $25-75 \%$ [3]. Especially in patients without a previous history of liver cirrhosis or HCC, diagnosing a ruptured tumor may be difficult, because of the missing patient history and the rare disease.

Here we report the case of an elderly patient with spontaneous ruptured advancedstaged HCC, which was detected for the first time in the emergency room and required a special approach.

\section{Case Presentation}

A 79-year-old man presented with an episode of upper gastrointestinal bleeding. A gastroscopy and a colonoscopy were performed, where an active bleeding was absent. Therefore, a duodenal polyp was suspected as the possible site of bleeding. Because of the platelet inhibition with aspirin, the polyp was not excised in this endoscopic session.

One week later, the patient presented again to the emergency department and complained of sudden abdominal pain in the upper quadrants. At the time of admission, the patient was cardiopulmonarily stable. In the clinical examination, there was a distinct tenderness on abdominal palpation in the upper right quadrant. In an interval of $4 \mathrm{~h}$, hemoglobin level decreased from 11.4 to $9.1 \mathrm{~g} / \mathrm{dL}$. There was no sign for coagulopathy (INR 1.1) and the liver enzymes (ALAT $16 \mathrm{U} / \mathrm{L}$, ASAT $26 \mathrm{U} / \mathrm{L}$, ALP $62 \mathrm{U} / \mathrm{L}$, bilirubin $3 \mu \mathrm{mol} / \mathrm{L}$ ) were normal. The performed X-ray of the abdomen excluded any free intraperitoneal air. In the presence of morphin-resistent pain, a contrast-enhanced computed tomography (CT) scan of the abdomen was performed. It showed a perforated tumor in segment IVb of the liver. The perforated tumor was actively bleeding into the peritoneal and mesenteric space (Fig. 1).

An emergent interdisciplinary discussion was initiated. To achieve hemostasis, we initiated a transarterial embolization (TAE). By a superselective angiography of the liver arteries with embolization of the segmental arteries IV and V with Embosphere particles (100-300 $\mu \mathrm{m})$, an adequate hemostasis was achieved. Although the tumor was highly vascularized, no active bleeding was seen during this intervention. The control showed a successful embolization (Fig. 2).

After clinical recovery of the patient, further radiological examinations were made. One month after diagnosis, the liver magnetic resonance imaging (MRI) showed a cirrhotic liver with a tumor of $85 \times 72 \times 75 \mathrm{~mm}$ in segment IV with a necrotic cavity, but no signs of further bleeding or ascites (Fig. 3). Six additional T2-hyperintense lesions with a maximum diameter of $11 \mathrm{~mm}$ were detected in segments II, III, and IVa/b. Metastatic disease was excluded by 


\section{Case Reports in Gastroenterology}

Case Rep Gastroenterol 2017;11:155-161 DOI: $10.1159 / 000463378$

(c) 2017 The Author(s). Published by S. Karger AG, Basel www.karger.com/crg

Gloor et al.: Acute Abdomen: A Rare Case of Ruptured Hepatocellular Carcinoma

thoracic and abdominal CT scan. Because of the tumor perforation and tumor size, an advanced-stage HCC according to the Milan criteria was diagnosed [5]. The tumor markers alpha-fetoprotein $(4 \mathrm{U} / \mathrm{mL}), \mathrm{CA} 19-9(15 \mathrm{U} / \mathrm{L})$, and CEA $(2.4 \mathrm{ng} / \mathrm{mL})$ were in the normal reference range. The serological findings were negative for hepatitis (HBVs antigen, HBV antibody, HCV antibody). Cirrhotic liver was classified as Child-Pugh A.

In the absence of a systemic progress, we decided for a selective transarterial radioembolization (TARE). During TARE planning, the gastroduodenal artery was coiled. In a second outpatient procedure, the whole liver was treated with a total of $6.2 \mathrm{GBq}(3.7 \mathrm{GBq}$ into the right liver lobe, $2.5 \mathrm{GBq}$ into the left liver lobe) in a split-dose fashion using yttrium-90 glass spheres (Therasphere, BTG).

One month later, the patient presented with a minimal tumor growth. Because of the slight progress, a follow-up after 2 months was initiated. This follow-up showed a significant regression of the primary tumor and the satellite lesions as well. Solely one new lesion in segment VII could be identified. Progressive disease with a growing primary tumor, satellite lesions, and an increase of alpha-fetoprotein $(47 \mathrm{U} / \mathrm{mL})$ was diagnosed 6 months after TARE (Fig. 3). Metastatic disease was excluded again. As a result, palliative treatment was implemented. A transarterial chemoembolization (TACE) of the left hepatic artery with doxorubicin $100 \mathrm{mg}$ was performed 1 month later. A planed MRI and chemoembolization of the right hepatic lobe were omitted due to the rapid deterioration of the patient's general health. Barely 2 weeks after TACE, the patient developed a septic cholangitis caused by an Enterococcus coli superinfection of the necrotic tumor. Despite an antibiotic therapy with piperacillin-tazobactam, the patient developed a multi-organ dysfunction. Therefore, we implemented a palliative therapy and the patient died 3 weeks after diagnosis of the cholangitis and almost 1 year after onset of symptoms.

\section{Discussion}

In this case report, we present a challenging patient who presented with an acute abdomen without a prior history of liver disease and was diagnosed with a ruptured HCC. This urgent diagnosis requires the emergency discussion with an interdisciplinary team to optimize the treatment.

In a situation of acute abdomen and a diagnosed HCC, the possible rupture of HCC must be included in the differential diagnosis. The abrupt onset of abdominal pain is the most common symptom in $66-100 \%$, followed by shock in 33-90\% of the patients [6]. Diagnosis should be made by sonography or CT, which can demonstrate the tumor and the hematoperitoneum. We use CT as standard examination because it can define the hypervascularization of tumors, the anatomy of hepatic arteries, the periportal lymph nodes, and the patency of the portal vein as well. Moreover, it is quickly available in the emergency setting.

For the new diagnosis of a ruptured HCC, an adequate workup is often missing in the emergency room. Additionally, hemorrhagic shock decreases liver function. The acute therapies include conservative treatment, TAE, and surgery. The decision-making depends on prognostic patient's factors, such as hepatic viral infection status, Child-Pugh grade, liver cirrhosis, and number of tumors. The management of a ruptured HCC in the acute phase aims to achieve hemostasis and preservation of functional liver parenchyma. Treatment options should be discussed on an interdisciplinary panel and is based on multiple factors (Fig. 4). Single-stage emergency liver resection has an in-hospital mortality of 16-100\% [3]. TAE is a good option to reach hemostasis in the acute situation of a ruptured HCC. The only 


\section{Case Reports in Gastroenterology}

Case Rep Gastroenterol 2017;11:155-161 DOI: $10.1159 / 000463378$

(c) 2017 The Author(s). Published by S. Karger AG, Basel www.karger.com/crg

Gloor et al.: Acute Abdomen: A Rare Case of Ruptured Hepatocellular Carcinoma

contraindication for TAE is a complete occlusion of the main portal vein by the tumor, which may cause hepatic infarction. Occluding the afferent vessels distally by TAE may achieve better hemostasis than surgery with a high success rate of 53-100\% [3]. In this case, a firstline surgical procedure was not feasible because of the unknown stage of the tumor, the missing etiology, and the disadvantages of an emergency resection. We decided to perform TAE of the tumor as a bridging therapy for further diagnostics and a significant improvement of overall survival [7].

The AJCC/UICC (American Joint Committee on Cancer/Union for International Cancer Control) classifies all ruptured HCCs as stage T4 in current TNM staging [8]. But outcomes may be better comparable in the pre-ruptured stage, e.g., ruptured T2 HCC have a significantly better overall survival than ruptured T3 and T4 HCC [7]. Liver resection is the only curative approach for patients with ruptured or non-ruptured HCC. To decide whether a tumor is resectable or not, a complete staging is essential. As a decision guideline, the Barcelona Clinic Liver Cancer classification (BCLC) may be used, which integrates tumor stage, liver function, and general conditions of the patient as well [9]. Generally, solely patients with Child A/B cirrhotic liver and without or with mild portal hypertension should have surgical resection. Otherwise, non-resectability is due to extrahepatic tumor, poor patient's condition and comorbidity, tumor infiltration into all liver veins, or lack of functional liver after resection [2]. In contrast to emergency procedure, staged liver resection has a much lower in-hospital mortality rate of 0-9\% [3]. Consequently, emergency liver resection should be reserved for patients with diagnosed HCC in which an R0 resection is possible and with sufficient liver function. In cases with insufficient functional liver, e.g., due to liver cirrhosis, transplantation may be evaluated. All Milan criteria must be fulfilled. Additionally, the tumor must be diagnosed by biopsy and either by an elevated alpha-fetoprotein level $(>400 \mathrm{U} / \mathrm{mL})$ and a hypervascularized tumor in radiology or by a hypervascularized tumor in two radiologic methods [10].

This patient did not qualify for surgical resection due to his advanced tumor stage. We decided for a bridging therapy to slow tumor progression. Normally, a duplication of tumor size is achieved in approximate 4 months [11]. The bridging therapy was started after reaching hemostasis and recovery of the patient. Radiofrequency ablation, TARE, TACE, or systemic chemotherapeutic sorafenib are such bridging procedures. These may bridge time towards transplantation, stop potential tumor growth, or even downstage a tumor. After interdisciplinary discussion, we decided to perform TARE. This decision was made because of the advanced tumor stage in combination with the missing systemic progression.

Decision-making in these complex patients has to be interdisciplinary, as many parameters change during the course of illness and non-operative options may be better suited to improve quality of life and survival.

\section{Conclusion}

TAE was able to stop the bleeding. Because of interval tumor progression, further transarterial therapies were applied (TARE and TACE). However, after 1 year after onset of symptoms, the patient died. During treatment of patients with ruptured HCC, it is of high importance that all involved physicians act as an interdisciplinary team. There are many factors in the decision-making process, which needed to be evaluated by specialists. The treatment of ruptured HCC needs to be a consensus of emergency doctors, gastroenterologists, interventional radiologists, and surgeons as well. 


\section{Statement of Ethics}

This study was performed in accordance with the ethical standards laid down in the 1964 Declaration of Helsinki and its later amendments.

\section{Disclosure Statement}

The authors declare that they have no competing interests.

\section{Author Contributions}

S.G., C.A.B., and E.A. cared for the patient. S.G. wrote the manuscript. C.A.B. provided the imaging material. K.O.J., S.B., C.A.B., F.H.H., and E.A. revised the manuscript critically for important intellectual content. All authors read and approved the final manuscript.

\section{References}

1 GLOBOCAN 2012 v1.0, Cancer Incidence and Mortality Worldwide. http://globocan.iarc.fr 2013.

$\longrightarrow 2$ Bruix J, Sherman M: Management of hepatocellular carcinoma: an update. Hepatology 2011;53:10201022.

-3 Lai EC, Lau WY: Spontaneous rupture of hepatocellular carcinoma: a systematic review. Arch Surg 2006;141:191-198.

4 Wittekind C, Meyer HJ, Bootz F (eds): TNM-Klassifikation maligner Tumoren. Springer 2010.

5 Mazzaferro V, Regalia E, Doci R, Andreola S, Pulvirenti A, Bozzetti F, Montalto F, Ammatuna M, Morabito A, Gennari L: Liver transplantation for the treatment of small hepatocellular carcinomas in patients with cirrhosis. New Engl J Med 1996;334:693-699.

6 Ong GB, Taw JL: Spontaneous rupture of hepatocellular carcinoma. Br Med J 1972;4:146-149.

7 Sada H, Ohira M, Kobayashi T, Tashiro H, Chayama K, Ohdan H: An analysis of surgical treatment for the spontaneous rupture of hepatocellular carcinoma. Dig Surg 2016;33:43-50.

8 Edge SB, Compton CC: The American Joint Committee on Cancer: the 7th edition of the AJCC cancer staging manual and the future of TNM. Ann Surg Oncol 2010;17:1471-1474.

-9 Greten TF, Manns MP: Hepatocellular carcinoma - diagnosis and treatment (in German). Dtsch Med Wochenschr 2008;133:1907-1910.

10 Leitlinienprogramm Onkologie: Diagnostik und Therapie des hepatozellulären Karzinoms, Langversion 1.0, AWMF Registrierungsnummer: 032-0530L. http://leitlinienprogrammonkologie.de/Leitlinien.7.0.html.

11 Sheu JC, Sung JL, Chen DS, Yang PM, Lai MY, Lee CS, Hsu HC, Chuang CN, Yang PC, Wang TH, et al: Growth rate of asymptomatic hepatocellular carcinoma and its clinical implications. Gastroenterology 1985;89:259-266. 


\section{Case Reports in Gastroenterology}
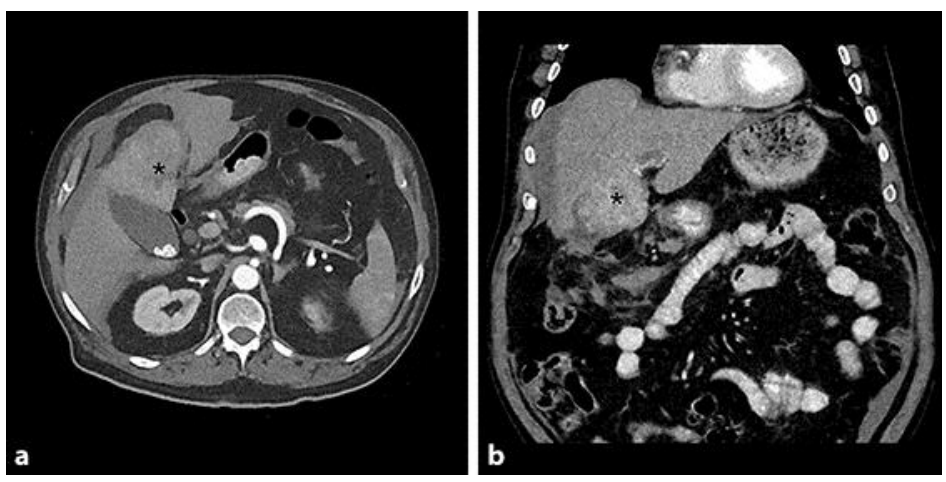

Fig. 1. Computed tomography of the abdomen. The axial plane (a) as well as the coronal plane (b) in the computed tomography scan of the abdomen showed a hepatic tumor (asterisk) with $6 \mathrm{~cm}$ diameter and perihepatic fluid.
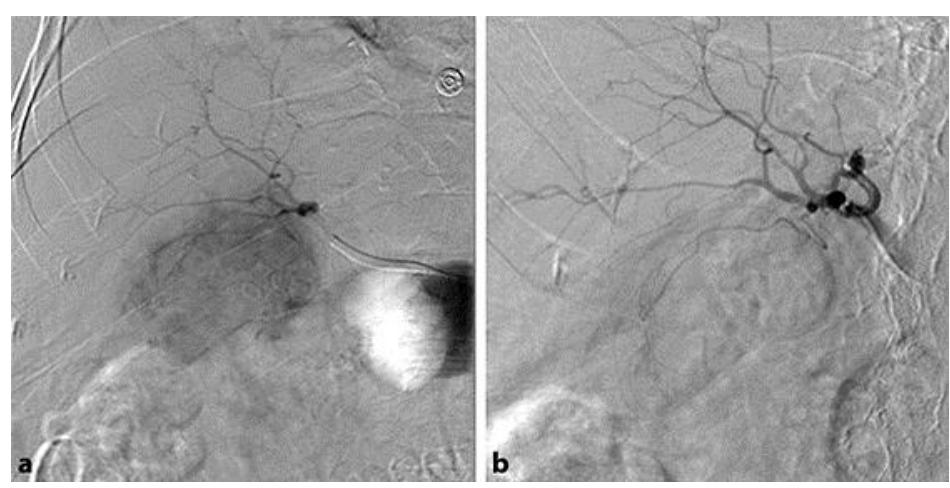

Fig. 2. Transarterial embolization. After puncture of the right femoral artery, a catheter was advanced via the celiac trunc into the common hepatic artery, and the segmental arteries IV and V were selectively embolized with particles (Embosphere 100-300 $\mu \mathrm{m}$ ). A highly vascularized tumor without active bleeding is shown in angiography before embolization (a) in segment IV. After tumor embolization, the former hypervascularity of the tumor is absent (b). 


\section{Case Reports in Gastroenterology}
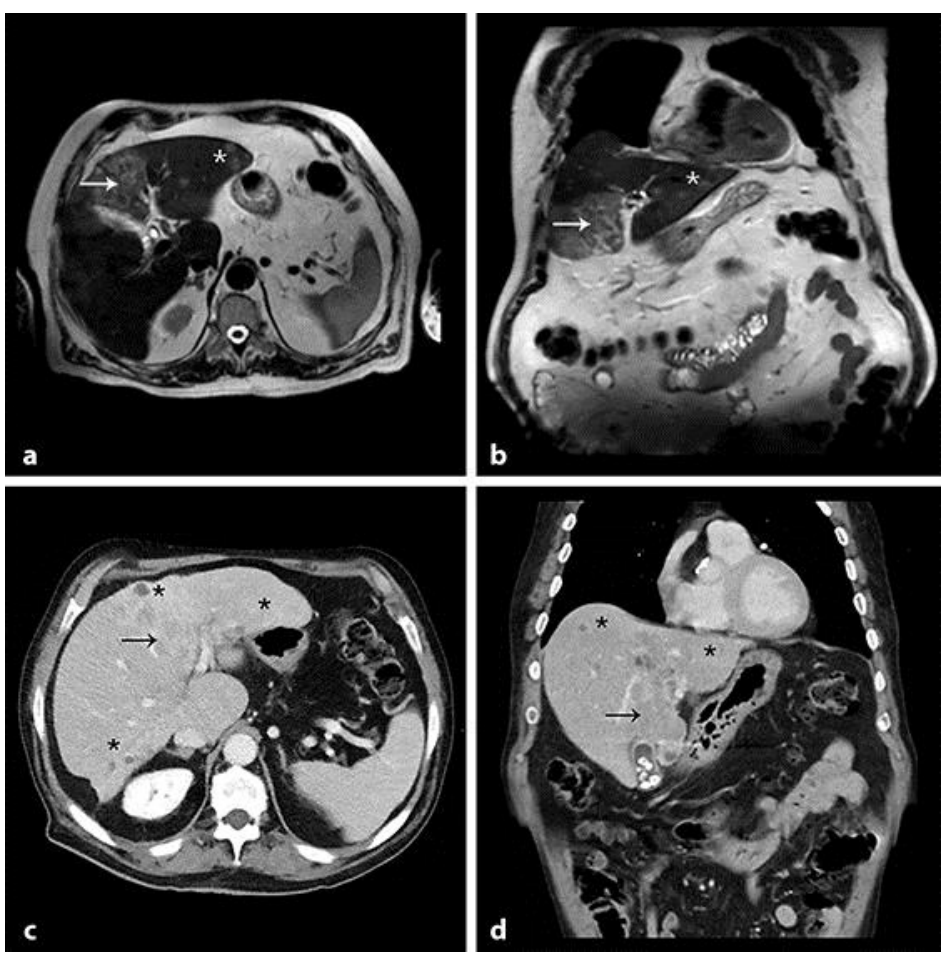

Fig. 3. Residual tumor in magnetic resonance imaging (T2) 1 month after embolization and progression especially in other parts of the liver in computed tomography of the abdomen 7 months after embolization. The axial plane (a) as well as the coronal plane (b) in the T2-weighted magnetic resonance imaging showed a residual tumor in segment IV (arrow) and several new tumors, here one shown in segment III (asterisk). After 7 months, multifocal appearance of the HCC on computed tomography with primary tumor (arrow) and smaller tumors (asterisk) in both lobes was seen on the axial plane (c) as well as the coronal plane (d).

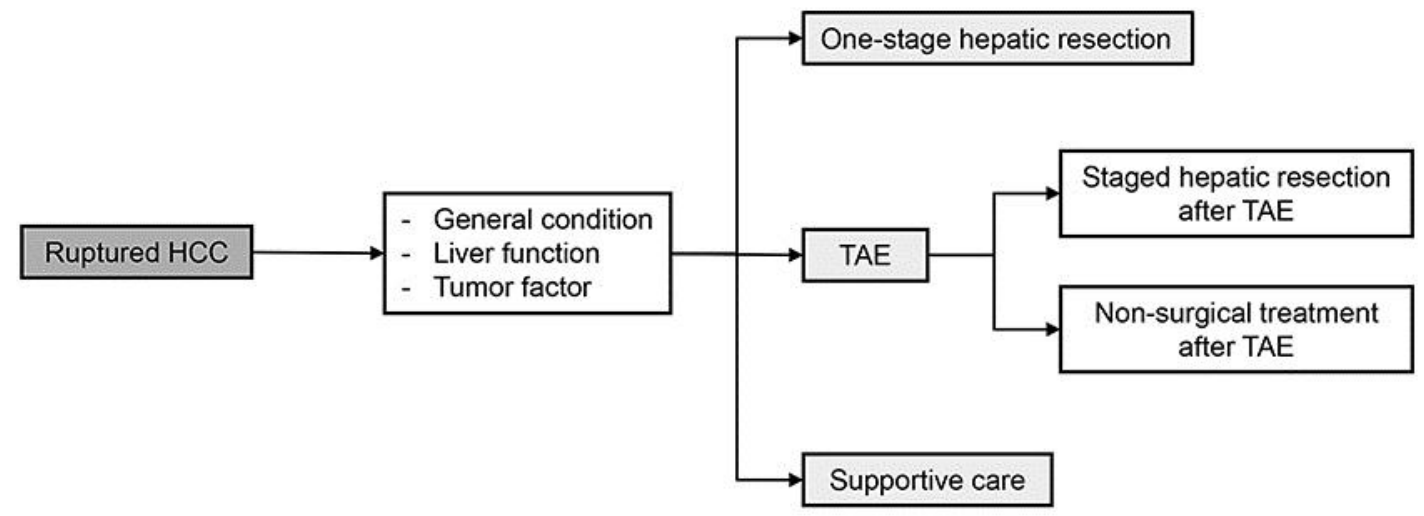

Fig. 4. Flowchart of emergency and definitive treatment of ruptured hepatocellular carcinoma. HCC, hepatocellular carcinoma; TAE, transarterial embolization. 